UDC 544.77: 546.74: 54-[31+36]: 576.[34+35+36]: 57.044: 613.6.027: 613.2.099

DOI: $10.21668 /$ health.risk/2021.2.17.eng

Read

online

Review

\title{
ASSESSING RISKS CAUSED BY NICKEL-BASED NANOMATERIALS: HAZARDOUS FACTOR IDENTIFICATION
}

\author{
I.V. Gmoshinski ${ }^{1}$, S.A. Khotimchenko ${ }^{1,2}$ \\ ${ }^{1}$ Federal Research Centre of Nutrition, Biotechnology and Food Safety, 2/14 Ustinsky lane, Moscow, 109240, \\ Russian Federation \\ ${ }^{2}$ I.M. Sechenov First Moscow State Medical University, 4 Bldg., 2 Bol'shaya Pirogovskaya Str., Moscow, 119435 , \\ Russian Federation
}

Nanoparticles of nickel (Ni) and its compounds attract a lot of attention bearing in mind their promising innovative properties allowing their use as catalysts, components in electrical appliances, electronic and photonic devices, and materials used in producing medications, diagnostic preparations, and pesticides. Production volumes of these materials in their nano-form are likely to grow rapidly in the nearest future and it involves greater loads created by these nanomaterials on a human body. And we should remember that Ni and its compounds are highly toxic for humans even in their traditional disperse forms. Their toxicity induces oxidative stress, cellular membranes and mitochondria dysfunction, expression of nuclear transcription factors that are responsible for apoptosis, caspases, as well as proto-oncogenes. Leading role in toxicity of $\mathrm{Ni}$-containing nanomaterials obviously belongs to ions of heavy $\mathrm{Ni}++$ being emitted from them since this heavy metal has pro-oxidant properties and influences enzyme activity and gene expression. Cytotoxic effects produced by Ni-containing nanomaterials were revealed in model experiments in vitro performed with suitable cellular cultures that were morphologically and functionally similar to epithelial cells of respiratory and gastrointestinal tract, liver, kidneys, and nervous system; these materials were able to stimulate oxidant stress, influence expression of apoptosis proteins and nuclear transcription factors, induce apoptosis and necrosis. There are data indicating that Ni-containing nanomaterials can produce malignant transforming effects in vitro. All the above mentioned proves that nickel compounds in their nanoform are a new hazardous factor that requires assessing related risks for workers, consumer, and population in general.

Our review focuses on analyzing literature sources on cytotoxicity of Ni-containing nanomaterials and their effects produced on molecular-genetic and cellular levels taken over a period starting from 2011.

Key words: nickel, nickel oxide, nanoparticles, cytotoxicity, genotoxicity, transforming ability, apoptosis, gene expression, risk assessment.

Nanoparticles (NPs) of nickel (Ni) and its compounds are given special attention since they seem promising for innovative use in engineering, consumer goods manufacturing, and in medicine. Starting from the beginning of the $20^{\text {th }}$ century, metallic Ni has been used as a catalyst in food and technical fats hydrogenation [1]. A basic drawback of this technological process is that it involves side creation of unsaturated fatty acids transisomers in substantial quantities; it happens owing to hydrogenation process being far from thermodynamic equilibrium since sub- strate molecules diffusion to nickel catalyst surface is kinetically limited. It is possible to substantially reduce these effects via using a catalyst based on nickel NPs immobilized on inert carriers (silicon dioxide or carbon) [2]. A wide range of such catalysts is reported to be synthesized and they contain NPs with their size being both less than 10 nanometers (so called cluster particles) and significantly greater [3]. Nano-structured Ni-containing catalysts are also applied in technologies involving fine organic synthesis, pharmaceutical industry included [4].

(C) Gmoshinski I.V., Khotimchenko S.A., 2021

Ivan V. Gmoshinski - Doctor of Biological Sciences, Leading researcher at the Laboratory for Food Toxicology and Nanotechnologies Safety Assessment (e-mail: gmosh@ion.ru; tel.: +7 (495) 698-53-71; ORCID: http: //orcid.org/00000002-3671-6508).

Sergey A. Khotimchenko - RAS Corresponding Member, Doctor of Medical Sciences, Professor, Head of the Laboratory for Food Toxicology and Nanotechnologies Safety Assessment (e-mail: hotimchenko@ion.ru; tel.: +7 (495) 698-52-35; ORCID: http: //orcid.org/0000-0002-5340-9649). 
Ni NPs are applied in electronics, electrical engineering and optoelectronics due to their unique magnetic and electrochemical properties. Thus, there are data on creating memory elements based on nano-rings made of Ni NPs [5]. Heterostructures based on Ni-NPs, NiO-NPs, as well as carbon nanotubes and graphene are used to make electrodes in rechargeable batteries with high electric capacity [6], multilayer ceramic super-condensers [7] and solar batteries [8]. Highly sensitive magnetic and chemical sensors have been developed that are based on Ni-containing nanoparticles [2]; these sensors are applied in medical diagnostics to detect tumor cells [9]. Ni NPs can be deliberately used in cosmetic products including tonal creams and dye stuff or accidentally penetrate into them [10]. Therapeutic use of Ni NPs and NPs of its alloys with copper includes controlled magnetic hyperthermia and theranostics [11]. Finally, there are some developments on using NPs of $\mathrm{Ni}$ and its compounds produced via biotechnological procedures as insecticides aimed at controlling population of mosquitoes that are communicable diseases carriers $[12,13]$.

In 2019 annual production of nano-sized $\mathrm{Ni}$ and its compounds was estimated as being equal to 20 tons only in the USA and tended to grow in future [14].

All these data indicate that NPs of Ni and its compounds are nanotechnological products with great prospects for their production to grow in the nearest future and it will unavoidably result in greater exposure to these nanomaterials, both for people and ecosystems [15]. Health risks that are likely to occur due to it are caused by $\mathrm{Ni}$ and its compounds being highly toxic even in their traditional dispersion. Multiple experimental and epidemiologic research works have revealed that metallic nickel and its compounds are carcinogenic (see early papers reviewed in [16]). Basing on these data IARC ranked $\mathrm{Ni}$ (II) compounds into Group 1 (carcinogenic for people) whereas metallic Ni is classified as Group 2B (possibly carcinogenic for people). $\mathrm{Ni}$ compounds are also known to be highly allergic [17]. After the paper by Kornick and Zug on nickel dermatitis epidemiology was published in 2008 [18] nickel was chosen as "the allergen of the year" by the American Contact Dermatitis Society.

There are growing concerns that NPs of $\mathrm{Ni}$ and its compounds may penetrate a body much more easily through respiratory tracts, gastrointestinal tract, or skin than their macrodisperse analogues due to their very small size; it may result in all the above mentioned adverse effects being aggravated. Ni nanoforms are especially alerting as adverse occupational factors (in chemical industry, metallurgy, electrical engineering and other branches) where risks caused by workers' exposure are the highest $[15,19]$.

All this indicates that it is necessary to assess potential health risks caused by Ni compounds in nanoform as independent adverse factors. According to the methodology applied in Russia ${ }^{1}$ risk assessment includes several necessary preliminary stages such as hazard factor identification and assessment of "dose response dependence, that is, qualitative characteristics of a hazard. The first element in risk assessment involves analyzing mechanisms of toxic effects, toxicity signs, and biomarkers that allow identifying adverse impacts exerted by an examined chemical on a body.

The goal of the present review was to analyze and generalize data on identifying Ni-containing nanomaterials as hazardous factors basing on results obtained via experiments in vitro and on assumed molecular-genetic, biochemical, and cytological mechanisms of their toxic effects. And the greatest attention is paid to data published over the last decade (starting from 2011) and available in sources that conform to conventional requirements regarding scientific validity and completeness and contained in international abstract databases PubMed, WoS and Scopus.

${ }^{1} \mathrm{R}$ 2.1.10.1920-04. The guide on assessing health risks for population under exposure to chemicals that pollute the environment. The Guide. Moscow, The Federal Center for State Sanitary and Epidemiologic Surveillance of the RF Public Healthcare Ministry Publ., 2004, 143 p. 
Cytotoxicity of Ni-containing nanomaterials. Cytotoxicity is understood in literature as an ability of substances to reduce cells viability and produce damaging effects on them at morphological and metabolic levels under incubation in vitro. As for NPs of Ni and its compounds, research on their cytotoxicity has been intensely accomplished starting from early 2000-ties [20]. Cytotoxicity studies do not give a direct answer to a question on a value of toxic doses for a body as a whole; however, they are useful, first of all, as a tool for screening potentially toxic nanomaterials and, secondly, they provide valuable data on molecular mechanisms and biomarkers of their effects produced on cells and, consequently, on a body as a whole.

Most toxicological studies in vitro are performed on unlimitedly dividing cells in a culture that, as a rule, are tumor ones. Nevertheless, all these cells have analogues among normal cells in organs and tissues and they are similar to these analogues as per morphofucntional, genome, and metabolome parameters. Therefore, it is quite relevant to consider available data in a sequence that reflects effects produced by Ni-containing NPs on cells in organs that are targets for effects produced by nanomaterials under actual exposure.

Respiratory organs cells. NPs of metallic $\mathrm{Ni}$ and $\mathrm{NiO}$, but not $\mathrm{Ni}$ microparticles (MPs), were captured by epithelial cells in the human lungs belonging to $\mathrm{H} 460$ line and primary cells in bronchial epithelium; $\mathrm{Ni}++$ ions were released from absorbed particles of both types [21]. Ni NPs, $\mathrm{NiO} \mathrm{NPs}$ and $\mathrm{NiCl}_{2}$ solution caused stabilization and nuclear translocation of transcription factor HIF-1 $\alpha$ induced by hypoxia and it resulted in elevated contents of its target NRDG1 (Cap43). Ni microparticles (MPs) didn't produce such effects whereas HIF- $1 \alpha$ activation caused by exposure to NPs was even more apparent than under exposure to a salt form. NiO NPs were equally toxic for cells from both lines, Ni microparticles were not toxic, and Ni NPs toxicity was intermediate. Caspases and poly- (ADP-ribose) polymerase were activated in all cases of toxicity that indicated apoptosis was developing.
NiO NPs turned out to be cytotoxic in experiments on human bronchial epithelial cells HEp-2 and breast cancer cells MCF-7 as they induced developing oxidation stress, glutathione quantity depletion, and lipid peroxides accumulation. There was caspases-3 activation, DNA fragmentation, and apoptosis markers expression. Effects produced by NPs on cells could be blocked by adding curcumin [22]. Micronucleuses appeared in lung epithelial cells of V79 hamster under exposure to NiO NPs sized $30 \mathrm{~nm}$ in concentrations equal to 250 and 2,500 $\mu \mathrm{g} / \mathrm{ml}$. DNA fragmentation was observed in a comet assay under exposure to NPs in concentration being equal to $62 \mu \mathrm{g} / \mathrm{ml}$ and higher [23].

$\mathrm{NiO}$ NPs toxicity was examined on two lines of human lung cells under exposure to doses varying from 20 to $100 \mu \mathrm{g} / \mathrm{ml}$; the research revealed that concentration of reactive oxygen species (ROS) grew already 45 minutes after exposure started; after 24 hours a significant number of cells died due to both necrosis and apoptosis [24]. It was accompanied with interleukins IL-6 and IL-8 appearing in large quantities and the process was mediated with MAPK kinase signal pathway that induced activity of NF-kB transcription factor. There was also disrupted cell cycle, genotoxic effects, and damage to DNA. All the above mentioned effects were observed both in A549 cells that absorbed NPs actively and in BEAS-2B cells though endocytosis was not typical for them.

In the work [25] performed on cells from A549 line NPs of $\mathrm{Ni}$ and $\mathrm{NiO}$ and $\mathrm{Ni}$ MPs caused changes in mitochondrial activity and increased cells proliferation; the effects were dose-dependent. When A549 cells were exposed to Ni NPs, it resulted in lower viability and damage to DNA; and it should be noted that metallic NPs had greater genotoxicity than MPs even in doses that were similar as per $\mathrm{Ni}$ contents, and they also stimulated greater oncogenes activation [26]. A549 cells exposure to sub-lethal NiO NPs doses was accompanied with signs of epithelial-mesenchymal transitions mediated with activation of TGF$\beta 1 /$ Smads - signal pathway. It was supported by stronger expression of type 1 collagen, TGF$\beta 1, \quad p-S m a d 2, \quad p-S m a d 3, \alpha$-actin, vimentin, 
E-cadherin and fibronectine, that is, changes that characterized fibrosis development at tissue level. SB431542 substance being an antagonist to TGF- $\beta 1$ was able to block these changes [27]. When A549 cells were exposed to $\mathrm{NiO}$ NPs (20 nm in diameter), there was a growth in expression of hemoxigenase-1 (HO-1) and surfactant protein-D, that is, genes regulated by hypoxia-induced transcription factor HIF-1 $\alpha$ [28]. These data coincided with those obtained on an alternative cell model in the work [21].

Oxidation stress induced by NiO NPs in A549 cells could be partially blocked by essential oil from Pistacia lentiscus that contained terpenoids [29].

BEAS-2B human bronchopulmonary epithelium cells were exposed to NiO NPs in concentrations equal to 5,10 and $20 \mu \mathrm{g} / \mathrm{ml}$; there was a decrease in expression of SIRT1 histone deacetylase and it resulted in gene p53 hyper-acetylation and $\mathrm{Bax}(\mathrm{Bcl}-2$ associated $\mathrm{X}$ protein) hyper-expression. An effect related in SIRT1 inhibition could be removed by resveratrol administration. These data indicate that SIRT1 can be a key molecule in developing cellular toxicity of Ni-containing nanomaterials [30]. When cells from this line were cultivated for 6 months with very low doses $(0.5 \mu \mathrm{g} / \mathrm{ml}$ as per Ni) of Ni NPs, NiO NPs, or $\mathrm{NiCl}_{2}$ salt, there were significant changes in trascriptome though cells viability was seemingly preserved [31]. The greatest number of genes (197) that responded via changes in their expression was detected for the salt form. There were changes in expression of S100A14 и S100A2 (Ca-binding proteins) genes as well as TIMP3, CCND2, EPCAM, IL4R and DDIT4 under exposure to all $\mathrm{Ni}$ forms. Bioinformatics analysis allowed revealing signal pathways of IL- $1 \alpha$, IL- $1 \beta$ and VEGF-A cytokines as targets for Ni nanoforms.

$\mathrm{Ni}$ and NiO NPs were effectively captured by BEAS-2B cells in a culture [32]. Unlike, $\mathrm{Ni}++$ ions penetrated into cells rather poorly. $\mathrm{Ni}$ and $\mathrm{NiO}$ nanoforms and $\mathrm{Ni}$ salt induced chromosome aberrations, DNA breaks, and intracellular ROS accumulation in exposed cells. It was accompanied with a growth in intracellular Ca quantity, and adding up chelat- ing agents resulted in lower genotoxicity signs. Genotoxicity and mutagenicity of Ni NPs (approximately $100 \mathrm{~nm}$ ) and $\mathrm{NiO}$ (approximately $50 \mathrm{~nm}$ ) in comparison with $\mathrm{NiCl}_{2}$ salt was examined for HBEC human bronchial epithelial cells via a comet assay and dyeing against $\gamma$ $\mathrm{H} 2 \mathrm{AX}$ (H2A histone family member X). Both NPs types aggregated intensely in a cultural medium. There was a growth in a number of DNA breaks under exposure to NiO NPs and to a lesser extent to Ni NPs; there were no such effects revealed under exposure to soluble Ni salt in comparable doses [33].

Cells of organs in the gastrointestinal tract. Intestine epithelium is among primary targets for NPs under oral exposure. In the work [34] toxicity of NiO NPs sized $15 \mathrm{~nm}$ was revealed in Caco-2 human cells culture that were similar to the small intestine enterocytes. NPs caused a $50 \%$ drop in cell survivability in a concentration equal to $352 \mu \mathrm{g} / \mathrm{ml}$; oxidation stress and damage to DNA, in a concentration equal to $30-150 \mu \mathrm{g} / \mathrm{ml}$. Apoptosis was a primary mechanism of cell death.

Human HepG2 cells that were hepatocytes analogues were exposed to NiO NPs (44 $\mathrm{nm}$ in diameter) and it resulted in dosedependent oxidation stress development and cells death, micronucleuses formation, chromatin condensation, Bax and caspases-3 expression, and Bcl-2 inhibition; it indicated that apoptosis was developing. All these processes were inhibited by ascorbic acid [35]. In the work [36] the same cell line was exposed to metallic Ni NPs that were $28 \mathrm{~nm}$ in diameter and in a concentration equal to $25-100 \mu \mathrm{g} / \mathrm{ml}$; it resulted in dose-dependent oxidation stress. A great number of cells in subG1 phase in cellular cycle was revealed under exposure to sub-lethal NPs dose and it indicated that apoptosis was induced. There was also caspase-3 expression and apoptotic DNA fragmentation, an increase in p53 expression and $\mathrm{Bax} / \mathrm{Bcl}-2$ ratio with simultaneous loss of mitochondrial membrane potential that indicated cell apoptosis was developing as per "mitochondrial" way.

Damage to DNA was analyzed in HepG2 cells via a comet assay; the analysis revealed that there was a 26-time increase in DNA 
fragmentation under exposure to NiO NPs in a concentration equal to $0.1 \mu \mathrm{g} / \mathrm{ml}$. Simultaneously flow cytometry revealed elevated ROS concentrations. There was also stronger expression of superoxide dismutase (SOD) as well as p53, Bax and $\mathrm{Bcl} 2$ [37]. Transcriptional analysis using total RNA-sequencing revealed [38] that changes in expression of HepG2 cells genes occurred when NiO NPs concentrations exceeded $5 \mu \mathrm{g} / \mathrm{ml}$. Expression of hypoxia-related HIF-1 $\alpha$ and micro-RNA(miR)210 grew under exposure to $25-100 \mu \mathrm{g} / \mathrm{ml}$ of these NPs; and there were variable changes in trascriptome including activations of glycolysis metabolic pathways, glutathione synthesis, lysosome digestion and autophagy even under exposure to concentrations that didn't cause any apparent cytotoxic effects. There was a growth in intracellular NO and calcium contents, and greater esterase activity as well as disorders in mitochondria membrane potential. Cell cycle deregulation became apparent via appearing $30.5 \%$ subG1 apoptotic peak. Therefore, cytotoxicity of NiO NPs for liver cells becomes apparent predominantly via hypoxia and oxidation stress that causes transcriptome changes, apoptosis, and DNA fragmentation.

Data in the work [39] indicate that NiO NPs may produce fibrogenic effects on liver cells; it was shown that HEPG2 cells exposure to these NPs in a concentration equal to $100 \mu \mathrm{g} / \mathrm{ml}$ resulted in elevated expression of TGF- $\beta 1$, p-Smad2, p-Smad3, $\alpha$-actin-smooth muscles, matrix metalloproteinase (MMP) of isoform 9, tissue inhibitor of metalloproteinase (TIMP)-1 and reduced E-cadherin and Smad7.

There was a single research work [40] that concentrated on comparing cytotoxicity of $\mathrm{Ni} \mathrm{NPs}, \mathrm{NiO} \mathrm{NPs}$, and $\mathrm{Ni}(\mathrm{OH})_{2} \mathrm{NPs}$ for bronchoalveolar A549 cells and hepatocytes-like HepG2 cells. Metallic Ni NPs turned out to be significantly more toxic for the first of these two lines, and there were no similar differences detected for oxide NPs. Basic cytotoxicity mechanisms were oxidation stress, disorder in mitochondrial membrane potential and caspase-3 synthesis induction that resulted in apoptosis development. Cytotoxicity of differ- ent NPs types given as per a nanomaterial mass correlated with their specific surface area and solubility in biological environment.

Kidney cells. An experiment on NRK-52E kidney tubule epithelial cells revealed that $\mathrm{NiO}$ NPs with average size being 10-20 nm and in a dose equal to $0-500 \mu \mathrm{g} / \mathrm{ml}$ were captured by cells and induced dose-dependent increase in contents of malonic dialdehyde, 8-oxo-2-deoxyguanosine (8-oxo-G) - DNA oxidation destruction product, and carbonylated protein, as well as glutathione reserves depletion. When concentrations of these NPs exceeded $290 \mu \mathrm{g} / \mathrm{ml}$, it resulted in death of more than $50 \%$ cells via both apoptosis and necrosis [41].

Skin cells. Metallic Ni NPs were cytotoxic and genotoxic for epidermal A431 human skin cells in concentrations varying from 2 to $20 \mu \mathrm{g} / \mathrm{ml}$ and exposure to them resulted in apoptosis and damage to DNA [42]. Cell death was accompanied with oxidation stress, glutathione reserves depletion, and caspase- 3 activation; these effects were inhibited by $\mathrm{N}$-acetylcysteine indicating that cell thiols, glutathione in particular, might probably have protective functions regarding toxic effects produced by NPs. There was an experiment when epidermal mice cells belonging to line JB6 were exposed to Ni NPs in a tetrazolium dye (MTT) assay; NPs turned out to be more cytotoxic in comparable concentrations than corresponding MPs. Both Ni forms caused apoptosis but NPs were more active [43]. Ni NPs induced expression of activator protein-1 (AP-1) and $\mathrm{NF}-\kappa \mathrm{B}$ in the same cells and these effects were inhibited by epigallocatechin-3-gallate (EGCG). EGCG was shown to weaken NPs cytotoxicity due to inhibiting a response by MAPK-signal pathway [44].

Immune cells. The work [45] concentrated on studying $\mathrm{NiO}$ cytotoxicity in lymphocytes extracted from human peripheral blood. Primary NPs size was $18 \mathrm{~nm}$; they aggregated intensely in water media. IC50 amounted to $24 \mu \mathrm{g} / \mathrm{ml}$ after 24 hours of exposure. A comet assay and micronucleuses analysis revealed that NPs were highly genotoxic. Lymphocytes primarily died via apoptosis induced by ROS and lipid peroxides production. 
Intact and oxide-passivated Ni NPs induced stronger expression of miR-21, MMP-2, MMP-9, as well as TIMP-1 and TIMP-2 in primary mice monocytes. These effects were not observed in mice cells with knocked-out gene miR-21 as well as in wild mice cells under exposure to Ni NPs covered with a carbon layer. These data indicate that miR-21 plays a significant role in inducing an inflammatory response to nickel NPs [46].

Reproductive system cells. An experiment performed on primary Sertolli cells of rat testis revealed that Ni NPs stimulated apoptosis with participating Igfbp3 genes, non-coding RNA LOC102551356 and mitochondrial mechanism. Igfbp3 is seen as a target gene in p53mediated apoptosis [47]. Effects produced by Ni NPS on Gc-1 line cells that were similar to mice stem sperm cells were accompanied with changes in ultra-structure, cell cycle delayed in phase G1, and activation of apoptosis as per inhibition of $\mathrm{PI} 3 \mathrm{~K} / \mathrm{AKT} / \mathrm{mTOR}$ signal pathway [48].

Embryonic cells. The work [33] concentrated on Ni NPs genotoxicity that became apparent via breaks in single-stranded DNA in mice embryonic stem cells belonging to line $\mathrm{mES}$ via using Hprt test based on reporter HPRT (Hypoxanthine Phosphoribosyltransferase) gene mutation; experiments were also performed on six lines of mice embryonic stem cells reconstructed in such a way so that they could respond with fluorescence to development of some genotoxicity and malignant transformation (so called "ToxTracker" assay). It is interesting that Ni NPs produced more apparent genotoxic effects in these systems in comparison with NiO NPs and Ni chloride solution.

Connective tissue cells. The work [49] dwelled on studying Ni NPs genotoxicity and mutagenicity for fibroblast cells of Chinese hamster lungs under exposure on the air-water interface. More than $50 \%$ cells died after 48-hour exposure to NPs in quantities equal to 0.15 and $0.32 \mu \mathrm{g} / \mathrm{cm}^{2}$ of the culture surface with a growth in a number of breaks in DNA chains and this growth was enhanced significantly after exposure to an inhibitor of singlestranded DNA reparation.
Neurons. NiO NPs with average diameter being $15.0 \mathrm{~nm}$ were captured in a dose-dependent way by neuron-like SH-SY5Y cells and caused death of $50 \%$ cells in a dose equal to $229 \mu \mathrm{g} / \mathrm{ml}$. There were morphological changes, a 3-11-time growth in DNA fragmentation and 80-99\% apoptosis together with oxidation stress [50]. The same NPs were shown in the work [51] to induce does-dependent apoptosis in cells from this line. To get an insight into effects produced by Ni-containing NPs on neurons, thermodynamic modeling was performed; it revealed how Ni NPs interacted with tau protein. As a result, there was expression of apoptosis gene Bax and in increase in Bax/Bcl-2 ratio, greater lactate dehydrogenase and caspases 3 and 9 activity. In further research [52] it was shown that exposure to NiO NPs in high doses induced oxidation stress and apoptosis of SH-SY5Y cells whereas in case doses were non-lethal, there was prevailing interaction between nanomaterial and tau-protein structures together with an increase in hydrophobic tau and formation of its amorphous aggregates.

Effects produced by $\mathrm{NiO}$ and $\mathrm{Mn}_{3} \mathrm{O}_{4} \mathrm{NPs}$ with diameters varying from 12 to $24 \mathrm{~nm}$ on neuronal human cells were examined via comparative analysis in the work [53]. To analyze multiple data that characterized cytotoxicity, response surface methodology was applied and it, according to the authors' opinion, allowed extrapolating obtained results onto effects produced by NPs in vivo. It was shown that $\mathrm{NiO} \mathrm{NPs}$ were less toxic for neuronal cells than $\mathrm{Mn}_{3} \mathrm{O}_{4} \mathrm{NPs}$; however, in case they were introduced together, NiO NPs made a prevailing contribution into cytotoxicity. The authors performed statistical analysis that revealed variable combined toxic effects depending on particles nature, size, and concentration. A primary factor that reduced cytotoxicity was NPs solubility in biological environment that decreased when fetal bovine serum was added to the examined cell cultures.

Transforming activity in vitro. Data obtained in some works discussed above indicate that exposure to NPs of Ni and Ni-containing compounds may induce processes similar to malignant transformation. Thus, the authors of the work [21] believe that persistent activation 
of HIF-1 $\alpha$ signal pathway in cells induced by $\mathrm{Ni}$ and NiO NPs may result in malignant transformation with subsequent tumor development in vivo. An experiment performed on epidermal mice cells JB6 [54] revealed that exposure to Ni NPS sized $50 \mathrm{~nm}$ led to activated synthesis of tumor transformation promoter activator protein-1 and NF- $\mathrm{BB}$ as well as elevated expression of R-Ras, c-myc, C-Jun, p65 and p50 that was not compensated with significantly lower expression of pro-apoptotic factor p53. The authors applied cultivating on soft agar and revealed that cells treated with Ni NPs tended to form colonies and it was considered to be similar to malignant growth. It is interesting that expression of p53 turned out to be a prevailing outcome in case cells were exposed to Ni MPs (micron-sized). Multiple DNA breaks detected in human bronchial epithelial cells exposed to NPs of $\mathrm{Ni}$ and $\mathrm{NiO}$ are also seen as a precondition of malignant transformation [33]. It is difficult to interpret facts obtained within in vitro systems since it was noted in most works that pro-apoptotic factors, including Akt-kinase and p53 were expressed simultaneously with oncogenes activation under exposure to Ni-containing nanomaterials [43]. Probable differences in assessing genotoxicity and transforming ability of $\mathrm{Ni}$ nanoforms in different test-systems in vitro might be related to differences between cell lines used in experiments regarding NPs capture by cells. Presumably, macropinocytosis or clathrin-mediated endocytosis are mechanisms used by cells to capture Ni NPs [55]. Particles absorption can depend on $\mathrm{Ca}++$ ions concentration in a cultivating medium as well as on particles sizes, charge and surface properties.

Besides, we should bear in mind that vast majority of data on genotoxicity and "carcinogenic" activity of Ni-containing nanomaterials were obtained via experiments on cell lines that were, to a greater or lesser degree, already transformed in comparison with their primary analogues. Therefore, it is obviously impossible to give an unambiguous answer to a question whether $\mathrm{Ni}$ and NiO NPs can produce carcinogenic effects if we rely solely on data obtained in experiments on cellular cultures.
Molecular and cellular cytotoxicity mechanisms. Data obtained via studies in vitro allow making well-substantiated conclusions on molecular and cellular cytotoxicity of Ni-containing NPs.

Oxidation stress. Oxidation stress develops due to imbalance between (predominantly fermentative) oxidation of organic substrates in metabolic processes and antioxidant system activity. The process is accompanied with ROS being synthesized in elevated quantities that exceed abilities of a body to eliminate them; it results in irreversible oxidative damage to proteins and membrane lipids. Excessive ROS can damage mitochondria which, due to that, can intensify ROS accumulation themselves; that is, oxidation stress can develop as per positive feedback mechanism with ultimate mitochondrial apoptosis activation [20].

Oxidation stress is seen as a basic nanotoxicity type and it occurs due to exposure to a great number of artificial nanomaterials. Some of them are relatively chemically inert and poorly soluble in biological media (for example, NPs of $\mathrm{Si}, \mathrm{Ti}, \mathrm{Ce}, \mathrm{Zr}$, and $\mathrm{Al}$ oxides) and exposure to them induces oxidation stress via non-fermentative catalytic ROS generation at an interphase surface between NPs and a medium [56]. In case of exposure to carbon nanotubes oxidation stress seems to develop due to hyperproduction of oxidants by cells (first of all, macrophages) that are primary targets for effects produced by this nanomaterial. Bearing in mind that Ni-containing NPs are highly soluble, we can assume that the latter of the above mentioned mechanisms is combined with influence exerted by $\mathrm{Ni}$ ions on fermentative systems that are responsible for balance between ROS synthesis and elimination [20].

Damage to cells and their membranes caused by effects produced by ROS can be a basic Ni NPs toxicity mechanism due to $\mathrm{Ni}++$ being able to bind to amino acids, polypeptides, and enzymes thus inducing ROS synthesis [57]. A contribution made by oxidation stress into cytotoxicity of Ni-containing NPs is also confirmed by multiple facts of their effects being inhibited by antioxidants introduction $[29,35,42,44]$. 
Apoptosis. Apoptosis is programmed cell death with a very complicated mechanism that includes actions performed by cysteine proteases family, proteins p53, Bcl-2, and others. There are two basic ways of apoptosis, namely death receptor way and mitochondrial way [20]. The first one basically involves apoptotic factor Fas (CD95) and Fas-associated death domain (FADD) protein creating a Fas-associated death-inducing signaling complex (DISC) with lamin A and $\beta$-actin disintegration that can bind and activate caspase- 8 and the following caspase-3. Mitochondrial apoptosis includes caspase-dependent and caspaseindependent pathway. The first of them involves Bax and Bak factors binding to mitochondria membranes thus releasing cytochrome $\mathrm{C}$ from them. It, in its turn, creates apoptotic complexes with adapter protein Apaf- 1 and caspase- 8 that activate caspase- 3 and the latter induces apoptosis. Caspaseindependent apoptosis flows as follows: a factor that induces apoptosis (AIF) is directly released by mitochondria into cytoplasm where it penetrates a nucleus and DNA is destroyed [16]. Apoptosis induced by NPs of Ni and its compounds includes both the death receptor way and those mediated by mitochondria. It follows from the data on an experiment on female rat ovaries exposed to Ni NPs where these particles simultaneously increased levels of such pro-apoptotic factors as caspase-3, caspase-8, caspase-9, Fas, Bax, Bid, cytochrome $\mathrm{C}$ and AIF and decreased levels of anti-apoptotic factor Bcl-2 [58]. As per data taken from the work [43], cytotoxicity of Ni NPs mostly develops due to apoptosis induced by a death receptor, namely, Fas activation. However, it was shown in the same work that Ni NPs activated Bcl-2 and, as a result, cytochrome $\mathrm{C}$ was not released from mitochondria into cytoplasm and this way of apoptosis didn't obviously occur.

Similar results were obtained in the works $[54,59]$, where it was shown that cytochrome $\mathrm{C}$ release was inhibited by Bcl-2 under exposure to Ni NPs. Bcl-2 is known to be a variety of proto-oncogene that can inhibit apoptosis [20]. Therefore, Ni NPs can paradoxically not only stimulate but also inhibit apoptosis due to
Bcl-2 activation and thus they induce cellular "carcinogenesis". It was also revealed [54, 59] that Ni NPs inhibited expression of proapoptotic factor p53. If p53 activation is reduced, apoptosis medicated by caspase- 3 and caspase- 8 is inhibited and it can ultimately result in tumor occurrence.

Damage to DNA and genotoxicity. Cell cycle is known to consist of four phases; they are DNA synthesis prophase (gap phase G0/G1), DNA synthesis phase (phase S), DNA synthesis anaphase (gap phase G2) and mitosis phase (phase M). Gap phase G0/G1 is a key to a proper start of a cell cycle. In case phase G0/G1 is blocked, cells will not go to mitosis and proliferation and it will ultimately result in apoptosis. Phase G0/G1 in human epidermal cells is blocked by Ni NPs in concentrations equal to 2.5 and $5 \mu \mathrm{g} / \mathrm{ml}$ and it leads to apoptosis whereas phase G2/M is blocked by Ni NPs in concentrations equal to 7.5 and $10 \mu \mathrm{g} / \mathrm{ml}$ and it results in a great number of DNA breaks [44]. These results provide an insight into a reason why low Ni NPs concentrations promote apoptosis whereas $\mathrm{Ni}$ NPs in high concentrations damage cellular DNA and induce mutagenesis with probable further malignant transformation.

MAPK signal pathway. MAPK signal pathway also known as mitogen-activated protein-kinase pathway includes three parallel pathways, namely ERK pathway, JNK/SAPKK pathway, and P38MAPK pathway. Further on the MAPK pathways for signal transfer there are two transcription factors, activator protein-1 (AP-1) and nucleus factor-jB (NF-jB) that participate in regulating multiple important cell activities such as proliferation, cells differentiation and apoptosis. AP-1 is a dimer that consists of c-Fos and c-Jun subunits and NF-jB is a dimer that consists of $\mathrm{p} 65$ and p50s subunits. Three MAPK pathways play an important role in carcinogenesis. ERK $1 / 2$ is activated via phosphorilation that regulates with c-Fos, c-myc and C-Jun thus increasing activity of transcription factor AP-1. Ultimate kinases JNK can also be activated via phosphorilation; they phosphorilate C-Jun and then AP-1. P38MARK phosphorilation results in $\mathrm{IjB}$ and $\mathrm{NF}-\mathrm{jB}$ depolymerization. Expression of R-Ras, c-myc, 
C-Jun, p65 and p50 proteins grows slowly under exposure to Ni NPs, moreover Ni NPs, in comparison with Ni MPs, are more likely to stimulate greater AP-1 and NF-jB activity [54]. Exposure to Ni NPs in concentrations being higher than $2.5 \mu \mathrm{g} / \mathrm{ml}$ resulted in a substantial increase in expression of phosphorilated ERK1/2 (p-ERK1/2), phosphorilated JNK (p-JNK) and phosphorilated P38 (p-P38) [44]. Therefore, Ni NPs turned out to be able to activate $\mathrm{AP}-1$ and $\mathrm{NF}-\mathrm{jB}$ in model in vitro systems via MAPK signal pathway and it could untimely result in malignant transformation.

HIF-1a signal pathway. Hypoxia-induced factor-1 (HIF-1) is a heterodimer that consists of HIF-1 $\alpha$ and HIF-1 $\beta$ subunits [20]. HIF-1 $\alpha$ is responsible for the complex activity and is initially localized in cytoplasm where as HIF$1 \beta$ is expressed both in cytoplasm and nucleoplasm and its function is to stabilize the active complex. HIF-1 $\alpha$ translocation into a nucleus under exposure to Ni-containing NPs is considered by some authors to be a key element in their fibrogenic, genotoxic, and transforming activity. As per data obtained in experiments on human monocytes exposure to Ni NPs in concentrations equal to 10 and $30 \mu \mathrm{g} / \mathrm{ml}$ resulted in an increase in contents of HIF-1 $\alpha$ that participated in MMP-2 and MMP-9 and TIMP-1 activation [60]. HIF-1 $\alpha$ pathway is assumed to participate in abnormal expression and changed activity of MMP induced by Ni NPs. Besides, HIF-1 $\alpha$ pathway activation may lead to malignant transformation of cells and tumor occurrence. Ni NPs are known to activate HIF-1 $\alpha$ pathway more intensely in comparison with Ni MPs or its soluble salt [21].

Figure shows a hypothetic chain of events occurring under exposure to Ni-containing nanomaterials at cellular level.

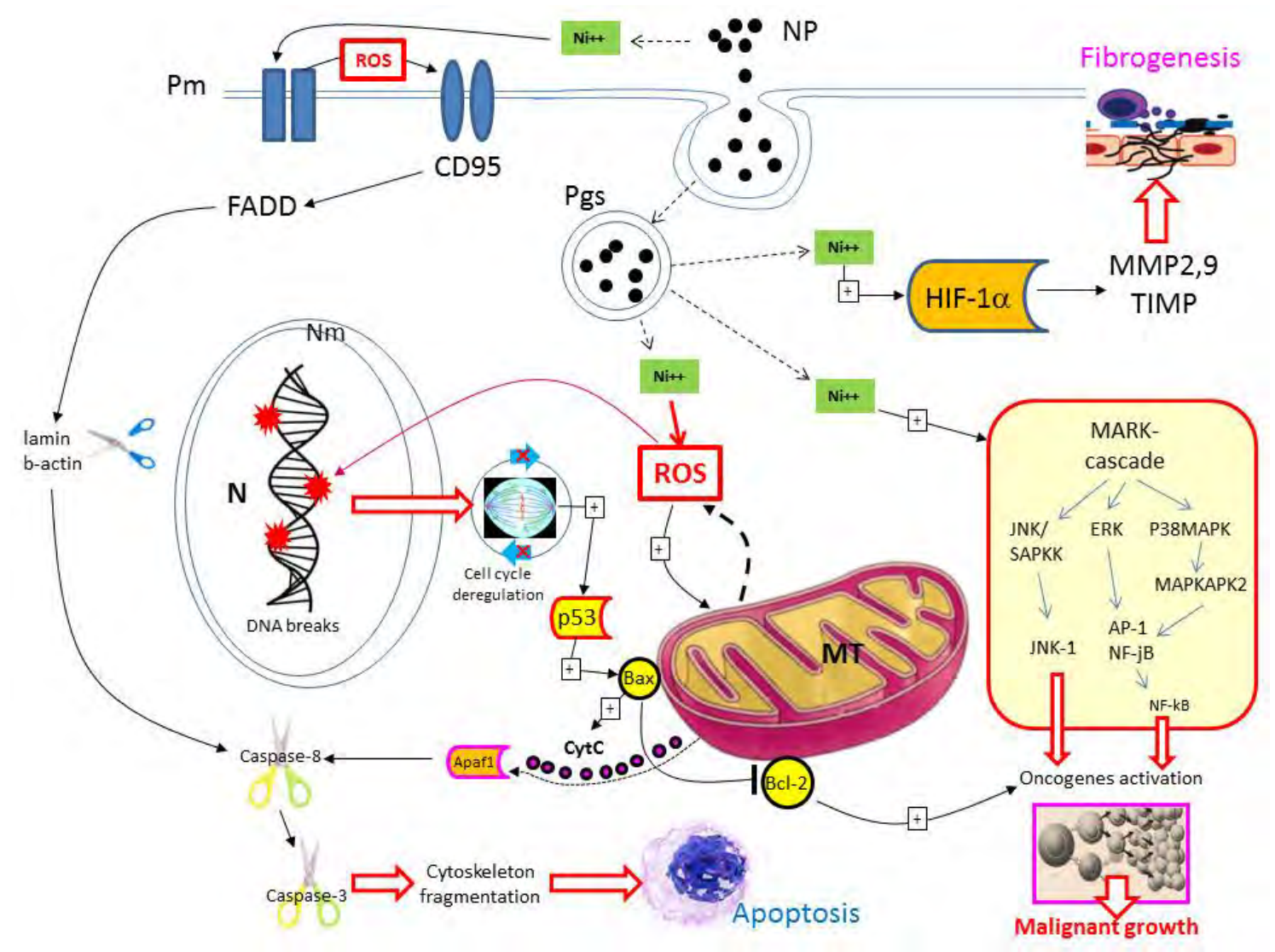

Figure. Basic outlines and targets of toxic effects produced by NPs of Ni and its compounds at cellular level

$\mathrm{N}$ o t e : NPs are nanoparticles; $\mathrm{Ni}++$, nickel ions; Pm, plasmatic membrane, Nm, nuclear membrane;

N, nucleus; MT, mitochondria; Pgs, phagosome/phagolysosome; ROS, reactive oxygen species;

$\dagger$, stimulation; $\rrbracket$, inhibition. 
Table 1

The most significant biomarkers showing cytotoxic effects produced by Ni-containing nanomaterials in vitro

\begin{tabular}{|c|c|c|c|c|}
\hline No. & Biomarker & Abbreviation & Cell model (analogue) & Source \\
\hline 1 & Hypoxia-induced factor & HIF-1 $\alpha$ & Lung epithelium cells & [21] \\
\hline 2 & A member of N-myc inhibited proteins family & NRDG1 & The same & [21] \\
\hline 3 & Nuclear transcription factor & $\mathrm{NF}-\kappa \mathrm{B}$ & The same & [24] \\
\hline 4 & Interleukins & $\begin{array}{c}\text { IL-1 } \alpha, \text { IL-1 } \beta, \text { IL-2, IL-6, } \\
\text { IL-8, INF- } \gamma\end{array}$ & The same & [24] \\
\hline 5 & Transforming growth factor & TGF- $\beta 1$ & The same & [27] \\
\hline 6 & Hemoxigenase 1 & $\mathrm{HO}-1$ & The same & [28] \\
\hline 7 & Apoptosis inhibitor & Bcl-2 & Liver cells & {$[35,43]$} \\
\hline 8 & Bcl-2-associated X-protein & Bax & Lung epithelium cells & [30] \\
\hline 9 & Matrix metalloproteinase & MMP 2, 9 & Liver cells, leukocytes & [39] \\
\hline 10 & Tissue inhibitors of metalloproteinase & TIMP 1,3 & Lung epithelium cells & [31] \\
\hline 11 & Interleukin 4 receptor & IL-4R & The same & [31] \\
\hline 12 & Micro-RNA 210 & $\operatorname{miR} 210$ & Liver cells, leukocytes & {$[38,46]$} \\
\hline 13 & 8-oxo-2-deoxyguanosine & 8-oxo-G & Kidney cells & [41] \\
\hline 15 & Tumor transformation promoter & AP-1 & Skin cells & [54] \\
\hline 16 & Proto-oncogenes & $\begin{array}{c}\text { R-Ras, C-myc, } \\
\text { C-Jun, p65, p50, JNK1 }\end{array}$ & Skin cells & [54] \\
\hline 17 & Apoptotic antigen 1 & Fas (CD95) & Skin cells & [43] \\
\hline
\end{tabular}

Table 1 summarizes data on the most informative biomarkers showing toxic effects produced by Ni-containing nanomaterials revealed in experiments on cell cultures.

Conclusion. Therefore, literature analysis has revealed that NPs of metallic nickel and its compounds $\left(\mathrm{NiO}, \mathrm{Ni}(\mathrm{OH})_{2}\right)$ as well as nickel nanofiber and nanorods are highly toxic. At cellular level such apparent toxicity signs are detected as oxidation stress, disorders in cellular membranes and mitochondria functions, expression of nuclear transcription factors that are responsible for apoptosis, caspases, as well as some proto-oncogenes. It is a paradox, but both apoptosis stimulation and its inhibitions with inducing malignant transformations are typical for NPs of Ni and its compounds at different doses. Presumably, these contradictory effects occur due to difference in sensitivity to high and low doses of $\mathrm{Ni}++$ ions in a chain of apoptosis that is mediated by mitochondrial Bax/Bcl-2 and a cascade of oncogenes activation via MAPKsignal pathway. There seems to be no principle differences in toxic effects produced by nanomaterials based on $\mathrm{Ni}$, its oxide, as well as its soluble salts (chloride, nitrate, and sulfate) on cells; so, we can conclude that it is
$\mathrm{Ni}++$ ions emission from them that plays the leading role in toxicity of these nanomaterials. Ni-containing nanomaterials differ substantially in this respect from those nanoparticles that are practically insoluble in biological media such as previously described nanoparticles of amorphous silicon dioxide [61] with the greatest contribution into their toxic effects being made by catalytic ROS generation on their surface; as well as partially soluble silver nanoparticles that exert intense influence on microelement homeostasis [62]. But at the same time, effective doses detected for NPs of Ni and its compounds turn out to be lower than those detected for its soluble salts and it highlights the significant role in cytotoxic effects that belongs to ability of these nanomaterials to penetrate into cells more easily.

The next necessary stage in risk assessment is to characterize a hazard, that is, to determine toxic and no-observed adverse effect levels (NOAEL) of an adverse chemical factor for different ways it can penetrate a body, that is, through respiratory organs, undamaged skin or gastrointestinal tract. Such data can't be obtained only via in vitro testing since such studies don't take into account biokinetic regulari- 
ties of an adverse factor, its ability to penetrate through biological area and bioaccumulation; so, it is necessary to perform experiments in vivo on laboratory animals as well as to generalize available data obtained via clinical observations. All these issues in relation to $\mathrm{Ni}$ containing nanomaterials will be dealt with in the next review.
Funding. This work was supported by the RF Ministry of Science and High Education, Research Program No 0529-2019-0057 "Development of quality and safety control system for foods including food additives and alcohol-containing drinks obtained by biotechnology methods".

Conflict of interests. The authors declare there is no any conflict of interests.

\section{References}

1. O'Braien R. Zhiry i masla. Proizvodstvo, sostav i svoistva, primenenie [Fats and oils. Manufacturing, structure and properties, use]. Sankt-Peterburg, Professiya Publ., 2007, 383 p. (in Russian).

2. Chang X., Zhu A., Liu F., Zou L., Su L., Li S., Sun Y. Role of NF- KB activation and Th1/Th2 imbalance in pulmonary toxicity induced by nano NiO. Environ. Toxicol, 2017, vol. 32, no. 4, pp. 1354-1362. DOI: 10.1002/tox.22329

3. Zhang P., Wang L., Yang S., Schott J.A., Liu X., Mahurin S.M., Huang C., Zhang Y. [et al.]. Solid-state synthesis of ordered mesoporous carbon catalysts via a mechanochemical assembly through coordination cross-linking. Nat. Commun, 2017, vol. 28, no. 8, pp. 15020. DOI: 10.1038/ncomms 15020

4. Bhattacharjee D., Sheet S.K., Khatua S., Biswas K., Joshi S., Myrboh B. A reusable magnetic nickel nanoparticle based catalyst for the aqueous synthesis of diverse heterocycles and their evaluation as potential antibacterial agent. Bioorganic. Medicinal. Chemistry., 2018, vol. 26, no. 18, pp. 5018-5028. DOI: 10.1016/j.bmc.2018.08.033

5. Zhu F.Q., Chern G.W., Tchernyshyov O., Zhu X.C., Zhu J.G., Chien C.L. Magnetic bistability and controllable reversal of asymmetric ferromagnetic nanorings. Phys. Rev. Lett, 2006, vol. 96, no. 2, pp. 027205. DOI: 10.1103/PhysRevLett.96.027205

6. Lei D., Lee D.C., Magasinski A., Zhao E., Steingart D., Yushin G. Performance enhancement and side reactions in rechargeable nickel-iron batteries with nanostructured electrodes. ACS Appl. Materials. Interfaces, 2016, vol. 8, no. 3, pp. 2088-2096. DOI: 10.1021/acsami.5b10547

7. Chou K.S., Chang S.C., Huang K.C. Study on the characteristics of nanosized nickel particles using sodium borohydride to promote conversion. Azo J. Mater. Online, 2007, vol. 3, pp. 172-179. DOI: 10.2240/azojomo0232

8. Bajpai R., Roy S., Kulshrestha N., Rafiee J., Koratkar N., Misra D.S. Graphene supported nickel nanoparticle as a viable replacement for platinum in dye sensitized solar cells. Nanoscale, 2012, vol. 4, no. 3, pp. 926-930. DOI: 10.1039/c2nr11127f

9. Wu X., Xiao T., Luo Z., He R., Cao Y., Guo Z. [et al.]. A micro-/nano-chip and quantum dots-based 3D cytosensor for quantitative analysis of circulating tumor cells. J. Nanobiotechnol., 2018, vol. 16, no. 1, pp. 65. DOI: 10.1186/s12951-018-0390-x

10. Borowska S., Brzóska M.M. Metals in cosmetics: implications for human health. J. Appl. Toxicol., 2015, vol. 35, no. 6, pp. 551-752. DOI: 10.1002/jat.3129

11. Ban I., Stergar J., Drofenik M., Ferk G., Makovec D. Synthesis of copper-nickel nanoparticles prepared by mechanical milling for use in magnetic hyperthermia. J. Magn. Magn. Mater., 2011, vol. 323, no. 17, pp. 2254-2258. DOI: 10.1016/j.jmmm.2011.04.004

12. Angajala G., Ramya R., Subashini R. In-vitro anti-inflammatory and mosquito larvicidal efficacy of nickel nanoparticles phytofabricated from aqueous leaf extracts of Aegle marmelos Correa. Acta Tropica., 2014, no. 135, pp. 19-26. DOI: 10.1016/j.actatropica.2014.03.012

13. Elango G., Roopan S.M., Dhamodaran K.I., Elumalai K., Al-Dhabi N.A., Arasu M.V. Spectroscopic investigation of biosynthesized nickel nanoparticles and its larvicidal, pesticidal activities. J. Photochem. Photobiol. B: Biology, 2016, vol. 162, pp. 162-167. DOI: 10.1016/j.jphotobiol.2016.06.045

14. Gomes S.I.L., Roca C.P., Scott-Fordsmand J.J., Amorim M.J.B. High-throughput transcriptomics: insights into the pathways involved in (nano) nickel toxicity in a key invertebrate test species. Environ. Pollut., 2019, no. 245, pp. 131-140. DOI: 10.1016/j.envpol.2018.10.123 
15. Katsnelson B., Privalova L., Sutunkova M.P., Gurvich V.B., Loginova N.V., Minigalieva I.A., Kireyeva E.P., Shur V.Y. [et al.]. Some inferences from in vivo experiments with metal and metal oxide nanoparticles: the pulmonary phagocytosis response, subchronic systemic toxicity and genotoxicity, regulatory proposals, searching for bioprotectors, a self-overview. Int. J. Nanomed, 2015, vol. 16, no. 10, pp. 3013-3029. DOI: 10.2147/IJN.S80843

16. Magaye R., Zhao J. Recent progress in studies of metallic nickel and nickel-based nanoparticles' genotoxicity and carcinogenicity. Environ. Toxicol. Pharmacol., 2012, vol. 34, no. 3, pp. 644-650. DOI: 10.1016/j.etap.2012.08.012

17. Ali A., Suhail M., Mathew S., Shah M.A., Harakeh S.M., Ahmad S., Kazmi Z., Alhamdan M.A.R. [et al.]. Nanomaterial induced immune responses and cytotoxicity. J. Nanosci. Nanotechnol., 2016, vol. 16, no. 1, pp. 40-57. DOI: 10.1166/jnn.2016.10885

18. Kornick R., Zug K.A. Nickel. Dermatitis, 2008, vol. 19, no. 1, pp. 3-8. DOI: $10.2310 / 6620.2008 .07082$

19. Garcia A., Eastlake A., Topmiller J.L., Sparks C., Martinez K., Geraci C.L. Nano-metal oxides: exposure and engineering control assessment. J. Occup. Environ. Hyg., 2017, vol. 14, no. 9, pp. 727-737. DOI: $10.1080 / 15459624.2017 .1326699$

20. Wu Y., Kong L. Advance on toxicity of metal nickel nanoparticles. Environ. Geochem. Health, 2020, vol. 42, no. 7, pp. 2277-2286. DOI: 10.1007/s10653-019-00491-4

21. Pietruska J.R., Liu X., Smith A., McNeil K., Weston P., Zhitkovich A., Hurt R., Kane A.B. Bioavailability, intracellular mobilization of nickel, and HIF-1 $\alpha$ activation in human lung epithelial cells exposed to metallic nickel and nickel oxide nanoparticles. Toxicol. Sci., 2011, vol. 124, no. 1, pp. 138-148. DOI: $10.1093 /$ toxsci/kfr206

22. Siddiqui M.A., Ahamed M., Ahmad J., Khan M.A.M., Musarrat J., Al-Khedhairy A.A., Alrokayan S.A. Nickel oxide nanoparticles induce cytotoxicity, oxidative stress and apoptosis in cultured human cells that is abrogated by the dietary antioxidant curcumin. Food Chem. Toxicol., 2012, vol. 50, no. 3-4, pp. 641-647. DOI: 10.1016/j.fct.2012.01.017

23. De Carli R.F., Chaves D.D.S., Cardozo T.R., de Souza A.P., Seeber A., Flores W.H., Honatel K.F., Lehmann M., Dihl R.R. Evaluation of the genotoxic properties of nickel oxide nanoparticles in vitro and in vivo. Mutat. Res. Genet. Toxicol. Environ. Mutagen, 2018, vol. 836, pt. B, pp. 47-53. DOI: $10.1016 /$ j.mrgentox.2018.06.003

24. Capasso L., Camatini M., Gualtieri M. Nickel oxide nanoparticles induce inflammation and genotoxic effect in lung epithelial cells. Toxicol. Lett, 2014, vol. 226, no. 1, pp. 28-34. DOI: $10.1016 /$ j.toxlet.2014.01.040

25. Latvala S., Hedberg J., Di Bucchianico S., Moller L., Odnevall Wallinder I., Elihn K., Karlsson H.L. Nickel release, ROS generation and toxicity of Ni and NiO micro- and nanoparticles. PLOS ONE, 2016, vol. 11, no. 7, pp. e0159684. DOI: 10.1371/journal.pone.0159684

26. Magaye R., Gu Y., Wang Y., Su H., Zhou Q., Mao G., Shi H., Yue X. [et al.]. In vitro and in vivo evaluation of the toxicities induced by metallic nickel nano and fine particles. J. Mol. Histol., 2016, vol. 47, no. 3, pp. 273-286. DOI: 10.1007/s10735-016-9671-6

27. Chang X., Tian M., Zhang Q., Gao J., Li S., Sun Y. Nano nickel oxide promotes epithelialmesenchymal transition through transforming growth factor $\beta 1 /$ smads signaling pathway in A549 cells. Environ Toxicol., 2020, vol. 35, no. 12, pp. 1308-1317. DOI: 10.1002/tox.22995

28. Horie M., Fukui H., Nishio K., Endoh S., Kato H., Fujita K., Miyauchi A., Shichiri M. [et al.]. Evaluation of acute oxidative stress induced by $\mathrm{NiO}$ nanoparticles in vivo and in vitro. J. Occup. Health, 2011, vol. 53, no. 2, pp. 64-74. DOI: 10.1539/joh.L10121

29. Khiari M., Kechrid Z., Klibet F., Elfeki A., Shaarani M.S., Krishnaiah D. NiO nanoparticles induce cytotoxicity mediated through ROS generation and impairing the antioxidant defense in the human lung epithelial cells, A549: preventive effect of Pistacia lentiscus essential oil. Toxicol. Rep., 2018, vol. 21, no. 5, pp. 480-488. DOI: 10.1016/j.toxrep.2018.03.012

30. Duan W.-X., He M.-D., Mao L., Qian F.-H., Li Y.-M., Pi H.-F., Liu C., Chen C.-H. [et al.]. $\mathrm{NiO}$ nanoparticles induce apoptosis through repressing SIRT1 in human bronchial epithelial cells. Toxicol. Appl. Pharmacol., 2015, vol. 286, no. 2, pp. 80-91. DOI: 10.1016/j.taap.2015.03.024 
31. Gliga A.R., Di Bucchianico S., Åkerlund E., Karlsson H.L. Transcriptome profiling and toxicity following long-term, low dose exposure of human lung cells to $\mathrm{Ni}$ and $\mathrm{NiO}$ nanoparticles-comparison with $\mathrm{NiCl}_{2}$. Nanomaterials (Basel), 2020, vol. 10, no. 4, pp. 649. DOI: 10.3390/nano 10040649

32. Di Bucchianico S., Gliga A.R., Åkerlund E., Skoglund S., Wallinder I.O., Fadeel B., Karlsson H.L. Calcium-dependent cyto- and genotoxicity of nickel metal and nickel oxide nanoparticles in human lung cells. Part. Fibre Toxicol., 2018, vol. 15, no. 1, pp. 32. DOI: 10.1186/s12989-018-0268-y

33. Åkerlund E., Cappellini F., Di Bucchianico S., Islam S., Skoglund S., Derr R., Wallinder I.O., Hendriks G., Karlsson H.L. Genotoxic and mutagenic properties of $\mathrm{Ni}$ and $\mathrm{NiO}$ nanoparticles investigated by comet assay, $\gamma$-H2AX staining, Hprt mutation assay and Tox Tracker reporter cell lines. Environ. Mol. Mutagen., 2018, vol. 59, no. 3, pp. 211-222. DOI: 10.1002/em.22163

34. Abudayyak M., Guzel E., Özhan G. Cytotoxic, genotoxic, and apoptotic effects of nickel oxide nanoparticles in intestinal epithelial cells. Turk. J. Pharm. Sci., 2020, vol. 17, no. 4, pp. 446-451. DOI: 10.4274/tjps.galenos.2019.76376

35. Ahamed M., Ali D., Alhadlaq H.A., Akhtar M.J. Nickel oxide nanoparticles exert cytotoxicity via oxidative stress and induce apoptotic response in human liver cells, HepG2. Chemosphere, 2013, vol. 93, no. 10, pp. 2514-2522. DOI: 10.1016/j.chemosphere.2013.09.047

36. Ahmad J., Alhadlaq H.A., Siddiqui M.A., Saquib Q., Al-Khedhairy A.A., Musarrat J., Ahamed M. Concentration-dependent induction of reactive oxygen species, cell cycle arrest and apoptosis in human liver cells after nickel nanoparticles exposure. Environ. Toxicol., 2015, vol. 30, no. 2, pp. 137-148. DOI:10.1002/tox.21879

37. Saquib Q., Siddiqui M., Ahmad J., Ansari S., Faisal M., Wahab R., Alatar A., Al-Khedhairy A.A., Musarrat J. Nickel oxide nanoparticles induced transcriptomic alterations in HEPG2 cells. Adv. Exp. Med. Biol., 2018, vol. 1048, pp. 163-174. DOI: 10.1007/978-3-319-72041-8_10

38. Saquib Q., Xia P., Siddiqui M.A., Zhang J., Xie Y., Faisal M., Ansari S.M., Alwathnani H.A. [et al.]. High-throughput transcriptomics: an insight on the pathways affected in HepG2 cells exposed to nickel oxide nanoparticles. Chemosphere, 2020, vol. 244, pp. 125488. DOI: 10.1016/j.chemosphere.2019.125488

39. Zhang Q., Chang X., Wang H., Liu Y., Wang X., Wu M., Zhan H., Li S., Sun Y. TGF- $\beta 1$ mediated Smad signaling pathway and EMT in hepatic fibrosis induced by Nano NiO in vivo and in vitro. Environ. Toxicol., 2020, vol. 35, no. 4, pp. 419-429. DOI: 10.1002/tox.22878

40. Cambre M.H., Holl N.J., Wang B., Harper L., Lee H.-J., Chusuei C.C., Hou F.Y.S., Williams E.T. [et al.]. Cytotoxicity of $\mathrm{NiO}$ and $\mathrm{Ni}(\mathrm{OH})_{2}$ nanoparticles is mediated by oxidative stressinduced cell death and suppression of cell proliferation. Int. J. Mol Sci., 2020, vol. 21, no. 7, pp. 2355. DOI: $10.3390 /$ ijms 21072355

41. Abudayyak M., Guzel E., Özhan G. Nickel oxide nanoparticles induce oxidative DNA damage and apoptosis in kidney cell line, NRK-52E. Biol. Trace Elem. Res, 2017, vol. 178, no. 1, pp. 98-104. DOI: $10.1007 / \mathrm{s} 12011-016-0892-\mathrm{z}$

42. Alarifi S., Ali D., Alakhtani S., Al Suhaibani E.S., Al-Qahtani A.A. Reactive oxygen speciesmediated DNA damage and apoptosis in human skin epidermal cells after exposure to nickel nanoparticles. Biol. Trace Elem. Res., 2014, vol. 157, no. 1, pp. 84-93. DOI: 10.1007/s12011-013-9871-9

43. Zhao J., Bowman L., Zhang X., Shi X., Jiang B., Castranova V., Ding M. Metallic nickel nano- and fine particles induce JB6 cell apoptosis through a caspase-8/AIF mediated cytochrome c-independent pathway. J Nanobiotechnol., 2009, vol. 7, pp. 2. DOI: 10.1186/1477-3155-7-2

44. Gu Y., Wang Y., Zhou Q., Bowman L., Mao G., Zou B., Xu J., Liu Y. [et al.]. Inhibition of nickel nanoparticles-induced toxicity by epigallocatechin-3-gallate in JB6 cells may be through down-regulation of the MAPK signaling pathways. PLoS One, 2016, vol. 11, no. 3, pp. e0150954. DOI: 10.1371/journal.pone.0150954

45. Dumala N., Mangalampalli B., Grover P. In vitro genotoxicity assessment of nickel(II)oxide nanoparticles on lymphocytes of human peripheral blood. J. Appl. Toxicol., 2019, vol. 39, no. 7, pp. 955-965. DOI: 10.1002/jat.3784 
46. Mo Y., Zhang Y., Mo L., Wan R., Jiang M., Zhang Q. The role of miR-21 in nickel nanoparticle-induced MMP-2 and MMP-9 production in mouse primary monocytes: in vitro and in vivo studies. Environ. Pollut., 2020, vol. 267, pp. 115597. DOI: 10.1016/j.envpol.2020.115597

47. Kong L., Hu W., Gao X., Wu Y., Xue Y., Cheng K., Tang M. Molecular mechanisms underlying nickel nanoparticle induced rat Sertoli-germ cells apoptosis. Sci. Total. Environ., 2019, vol. 692, pp. 240-248. DOI: 10.1016/j.scitotenv.2019.07.107

48. Wu Y., Ma J., Sun Y., Tang M., Kong L. Effect and mechanism of PI3K/AKT/mTOR signaling pathway in the apoptosis of GC-1 cells induced by nickel nanoparticles. Chemosphere, 2020, vol. 255, pp. 126913. DOI: 10.1016/j.chemosphere.2020.126913

49. Latvala S., Vare D., Karlsson H.L., Elihn K. In vitro genotoxicity of airborne Ni-NP in airliquid interface. J. Appl. Toxicol., 2017, vol. 37, no. 12, pp. 1420-1427. DOI: 10.1002/jat.3510

50. Abudayyak M., Guzel E., Özhan G. Nickel oxide nanoparticles are highly toxic to SH-SY5Y neuronal cells. Neurochem. Int., 2017, vol. 108, pp. 7-14. DOI: 10.1016/j.neuint.2017.01.017

51. Hajimohammadjafartehrani M., Hosseinali S.H., Dehkohneh A., Ghoraeian P., Ale-Ebrahim M., Akhtari K., Shahpasand K., Saboury A.A., Attar F., Falahati M. The effects of nickel oxide nanoparticles on tau protein and neuron-like cells: biothermodynamics and molecular studies. Int. J. Biol. Macromol., 2019, vol. 127, pp. 330-339. DOI: 10.1016/j.ijbiomac.2019.01.050

52. Hosseinali S.H., Boushehri Z.P., Rasti B., Mirpour M., Shahpasand K., Falahati M. Biophysical, molecular dynamics and cellular studies on the interaction of nickel oxide nanoparticles with tau proteins and neuron-like cells. Int. J. Biol. Macromol., 2019, vol. 125, pp. 778-784. DOI: 10.1016/j.ijbiomac.2018.12.062

53. Minigalieva I., Bushueva T., Fröhlich E., Meindl C., Öhlinger K., Panov V., Varaksin A., Shur V. [et al.]. Are in vivo and in vitro assessments of comparative and combined toxicity of the same metallic nanoparticles compatible, or contradictory, or both? A juxtaposition of data obtained in respective experiments with $\mathrm{NiO}$ and $\mathrm{Mn}_{3} \mathrm{O}_{4}$ nanoparticles. Food Chem Toxicol., 2017, vol. 109, pt. 1, pp. 393-404. DOI: 10.1016/j.fet.2017.09.032

54. Magaye R., Zhou Q., Bowman L., Zou B., Mao G., Xu J., Castranova V., Zhao J., Ding M. Metallic nickel nanoparticles may exhibit higher carcinogenic potential than fine particles in JB6 cells. PLoS One, 2014, vol. 9, no. 4, pp. e92418. DOI: 10.1371/journal.pone.0092418

55. Muñoz A., Costa M. Elucidating the mechanisms of nickel compound uptake- a review of particulate and nano-nickel endocytosis and toxicity. Toxicol. Appl. Pharmacol., 2012, vol. 260, no. 1, pp. 1-16. DOI: 10.1016/j.taap.2011.12.014

56. Manke A., Wang L., Rojanasakul Y. Mechanisms of nanoparticle-induced oxidative stress and toxicity. Biomed. Res. Int., 2013, vol. 2013, pp. 942916 . DOI: 10.1155/2013/942916

57. Cameron K.S., Buchner V., Tchounwou P.B. Exploring the molecular mechanisms of nickel-induced genotoxicity and carcinogenicity: a literature review. Rev. Environ. Health, 2011, vol. 26, no. 2, pp. 81-92. DOI: 10.1515/reveh.2011.012

58. Kong L., Gao X., Zhu J., Cheng K., Tang M. Mechanisms involved in reproductive toxicity caused by nickel nanoparticle in female rats. Environ. Toxicol., 2016, vol. 31, no. 11, pp. 1674-1683. DOI: $10.1002 /$ tox.22288

59. Magaye R.R., Yue X., Zou B., Shi H., Yu H., Liu K., Lin X., Xu J. [et al.]. Acute toxicity of nickel nanoparticles in rats after intravenous injection. Int. J. Nanomed., 2014, vol. 9, pp. 1393-1402. DOI: $10.2147 /$ ijn.S56212

60. Wan R., Mo Y., Chien S., Li Y., Tollerud D.J., Zhang Q. The role of hypoxia inducible factor- $1 \alpha$ in the increased MMP-2 and MMP-9 production by human monocytes exposed to nickel nanoparticles. Nanotoxicology, 2011, vol. 5, no. 4, pp. 568-582. DOI: 10.3109/17435390.2010.537791

61. Shumakova A.A., Shipelin V.A., Trushina E.N., Mustafina O.K., Gmoshinskii I.V., Khanfer'yan R.A., Khotimchenko S.A., Tutel'yan V.A. Toxicological assessment of nanostructured silica. IV. Immunological and allergological indices in animals sensitized with food allergen and final discussion. Voprosy pitaniya, 2015, vol. 84, no. 5, pp. 102-111 (in Russian). 
62. Gmoshinski I.V., Shumakova A.A., Shipelin V.A., Maltsev G.Yu., Khotimchenko S.A. Influence of orally introduced silver nanoparticles on content of essential and toxic trace elements in organism. Nanotechnologies in Russia, 2016, vol. 11, no. 9-10, pp. 646-652. DOI: $10.1134 / \mathrm{S} 1995078016050074$

Abbreviations: 8-oxo-G - 8-oxo-2-desoxyguanosine; MMP - matrix metalloproteinase; MP microparticles; NP - nanoparticles; ROS - reactive oxygen species; Bax - Bcl-associated X-protein; Bcl-2 - intracellular apoptosis regulator; HIF - hypoxia-induced factor; HO-1 - hemoxygenase-1; IARC - Internaitonal Agency for Research on Cancer; IC50 - 50 \% inhibition concentration; IL - interleukin; INF - interferon; MAPK - mitogen-activated protein kinase; miR - micro-RNA; p53 - apoptosis stimulating factor; SOD - superoxide dismutase; TGF - transforming growth factor; TIMP - tissue inhibitor of metalloproteinase

Gmoshinski I.V., Khotimchenko S.A. Assessing risks caused by nickel-based nanomaterials: hazardous factor identification. Health Risk Analysis, 2021, no. 2, pp. 173-187. DOI: 10.21668/health.risk/2021.2.17.eng

Received: 07.04.2021

Accepted: 07.06.2021

Published: 30.09 .2021 